\title{
2018 Best Zone II Paper: Comparison of Student and Faculty Perceptions of Intent and Effectiveness of Course Evaluations in an Engineering Curricu- lum
}

\section{Dr. Thomas P. James P.E., Rose-Hulman Institute of Technology}

Tom James is presently a Professor of Entrepreneurship at Rose-Hulman Institute of Technology. His major interests are new product development and global business ventures. He currently teaches courses in accounting, finance, and entrepreneurial studies. In addition to teaching, Dr. James directs the ESCALATE program, a living-learning community focused on integrating entrepreneurship and technical disciplines. He received his $\mathrm{PhD}$ in Mechanical Engineering and an Executive MBA from Marquette University. He is a Fellow of the American Society of Mechanical Engineers and is a registered Professional Engineer (PE). Dr. James is also an avid inventor with over two dozen patents and he has several publications in peer reviewed journals related to his research in biomechanical systems. Prior to joining academia, he worked for over a decade in the consumer products industry, most recently as Senior Vice President of Global Engineering at Techtronic Industries, headquartered in Hong Kong, where he lived with his family for several years. 


\title{
Comparison of Student and Faculty Perceptions of Intent and Effectiveness of Course Evaluations in an Engineering Curriculum
}

\author{
John Michael Van Teeck and Thomas P. James
}

Rose-Hulman Institute of Technology, Terre Haute, IN

\begin{abstract}
This paper provides a comparison between a student's apparent belief system and faculty perceptions of the intent and effectiveness of course evaluations. Data collection was through a survey instrument and in-person interviews. The focus of information gathering was directed toward how student course evaluations may have impacted faculty teaching methodologies, choice of course materials, and content of curriculum from both a scale and timing viewpoint. The results from this research are useful for those interested in examining gaps that may exist between student and faculty perceptions related to the usefulness of course evaluations. In particular, the conclusions drawn from the data are applicable to educators of newly matriculated students when introducing and setting expectations for their institute's course evaluation system, for example during a first semester College and Life Skills course.
\end{abstract}

\section{Keywords}

Course Evaluation, Teacher Evaluation, Assessment 


\section{Introduction}

The use of course evaluations in an academic environment to improve courses and to evaluate faculty performance is a mainstay at most universities. For tenure track faculty in particular, they must recognize and perhaps wrestle with the notion that a student's evaluation of their courses and teaching performance will be an important consideration in their path to tenure at the academy, as represented by the teaching-service-professional development triad. Unfortunately, the majority of new doctoral faculty entering engineering bachelor degree academic programs have scant experience in the classroom beyond a graduate school Teaching Assistantship, which typically lasts only a few semesters as doctoral candidates bide their time in anticipation of being offered a Research Assistantship for the duration of their graduate studies. ${ }^{1,2}$

During the learning curve for faculty, the course evaluation process can create tension between the student and the professor, as both parties are needed to advance and to improve the other through mutual assessment. While professors have the upper hand in assessment at a course level, student's often get the final word when completing course evaluations or resorting to websites like RateMyProfessors.com ${ }^{\circledR}$. While it is likely that website banter about professors has little impact on tenure and promotion committee deliberations, it certainly sets a mood and expectation for a student. First impressions matter, especially those delivered online to students.

In notable cases, the tension can lead to professors manipulating student opinions through their perception of bias that may exist, for example by "dumbing down the course" or by offering curves and extra credit before evaluations are released to the students. ${ }^{3}$ However, as Warren Hill reports, a common misconception is that students are more likely to give high performing evaluations to well liked professors and to professors that give out higher grades. ${ }^{4}$ It is also a misconception that students will give out better teaching evaluations to professors that have reduced workloads in their classes. ${ }^{5}$

A more positive outlook on the course evaluation system suggests professors and students can create a personal bond, which increases the likelihood of a student becoming more interactive in class, engaged in their learning, and more helpful with comments on their course evaluations. ${ }^{6}$ Dr. Donald Visco's work, Improving Student Evaluations: Demonstrating Concern for Students, mentions:

... Demonstrate concern for [your students] well-being and, perhaps, put them more at ease in your office. The benefit, of course, is they will be more likely to come to your office to discuss things they don't understand in the course in the future. ${ }^{7}$

The ability to connect to a student and to show interest in them not only improves faculty course evaluation scores, ${ }^{3}$ but also incubates active learning, which leads to a better understanding and higher test scores ${ }^{8}$. In turn, the increase in grades will cause students to be more appraising on their course evaluations. ${ }^{9}$ This creates a cycle where becoming a more active professor in a student's life helps improve their engagement, their grades, and in turn the faculty member's evaluation scores. 
In this vein of a more positive faculty perspective, course evaluations play a supportive role in the tenure process as comments from students aid in perfecting the craft of teaching. Continuous adjustments to teaching practice, in pursuit of learning effectiveness, can only happen through a supportive feedback loop. However, a contemporary concern, raised by the authors in the form of a hypothesis for this preliminary research, is that millennials may be more conditioned than previous cohorts to think their digital feedback will have an immediate and positive change in teaching performance. After all, this year's matriculating students likely represent the first wave of the smartphone generation (meaning the first wave of students that have missed the flip phone stage and have always had reliable handheld access to the internet). This cohort is wielding their handheld assessment tool to instantly give star ratings of products or written reviews of services on various social media sites. To them, an online course evaluation may simply be an extension of this conditioned behavior, where a series of negative reviews pouring in online can immediately decimate product sales or crater a restaurant's opening week. When they speak, something happens relatively quickly.

Given matriculation of the smartphone generation, we sought to understand through a survey instrument if there are noticeable differences or "gaps" between faculty and student perceptions of the intent and effectiveness of course evaluations. In addition, we hypothesized that there may be a temporal shift in how students feel about course evaluations, with freshman being more idealistic than seniors, for example. Finally, we were interested to see if there was a gender effect, meaning that male and female students may view the course evaluation feedback process differently.

\section{Research Methods and Data Collection}

An online survey instrument was created and distributed at our institution with a response goal of 10 percent of the faculty and 10 percent of the undergraduate student body. The goal for student responses was to have an equal number from each of the traditional four academic years. A secondary goal was to have the gender and academic majors of the student respondent population mirror institutional balance. Finally, the timing of the survey was critical as we needed to reach newly matriculated students prior to completing their first course evaluations on campus.

The survey contained ten Likert items, where each item was a statement that reflected one of the ten questions from our current online course evaluation. The online course evaluation is shown in Appendix A, while the survey statements we developed are shown in Appendix B. To eliminate acquiescence bias, where a respondent may be inclined to agree with statements as written, framing of the statements was done in both the affirmative and the negative. Following convention, a five point Likert scale was used, where possible responses were: Strongly Disagree, Disagree, Neither Agree nor Disagree, Agree, and Strongly Agree. Additional questions were included in the survey to collect information about a respondent's gender, declared major, and year in school.

To gain a more in depth understanding of faculty perspectives and to reduce the possibility of social desirability bias, where a person tends to put their organization in a favorable light, oneon-one interviews were conducted with several faculty members. In these interviews, faculty members described their experience with course evaluations and conveyed their perception on 
how seriously students take course evaluations. An account was also given on how faculty have used course evaluations to make changes to either their teaching style or their courses. Faculty members selected for interviewing came from a variety current employment statuses. For example, some professors that were interviewed had tenure, some were new professors, and other professors were interviewed specifically to talk about their experience with designing a new course and how course evaluations changed successive offerings of the new course.

Finally, students were selected for one-on-one interviews to describe their experiences with course evaluations or their perceptions of what a course evaluation is used for in the case of freshman that have never completed a course evaluation. These interviews specifically probed the issue of what students think faculty do with their course evaluations, and to gather primary data on what students think are the pros and cons of the existing online course evaluation system.

SurveyMonkey.com ${ }^{\circledR}$ was used was to electronically distribute the survey to students and faculty. The response data was exported from SurveyMonkey and imported into Microsoft Excel $\circledR$, where it was treated as ordinal data and analyzed graphically by frequency of response. The Internal Review Board at our institution waived full board review and granted approval for campus dissemination of the survey instrument. Prior to taking the survey, respondents were asked to electronically indicate their acceptance to a consent statement or to opt out.

\section{Results and Discussion}

One hundred ninety five students and twenty faculty responded to the survey, Table 1. Six faculty and five students were interviewed. Four of the six interviewed faculty had tenure. An oversight on the survey instrument was that we did not ask the faculty if they had tenure so we could not make downstream comparisons on this basis.

Table 1: Students and faculty members that responded to questions by survey and interview.

\begin{tabular}{c|ccc|cccc}
\hline \hline Source & Male & Female & Tenure & Male & Female & Freshman & $\begin{array}{c}\text { Upper- } \\
\text { classman }\end{array}$ \\
\hline Interviewed & 3 & 3 & 4 & 3 & 2 & 2 & 3 \\
\hline $\begin{array}{c}\text { Survey } \\
\text { Respondent }\end{array}$ & 13 & 7 & $X$ & 127 & 67 & 49 & 146 \\
\hline \hline
\end{tabular}

\section{Gender of the Student}

When comparing male and female student responses, there showed a tendency for women to steer away from picking "Strongly Agree" or "Strongly Disagree" as a response. Figure 1 demonstrates the percent of males and females who responded with "Strongly Agree" to each of the ten survey items. 


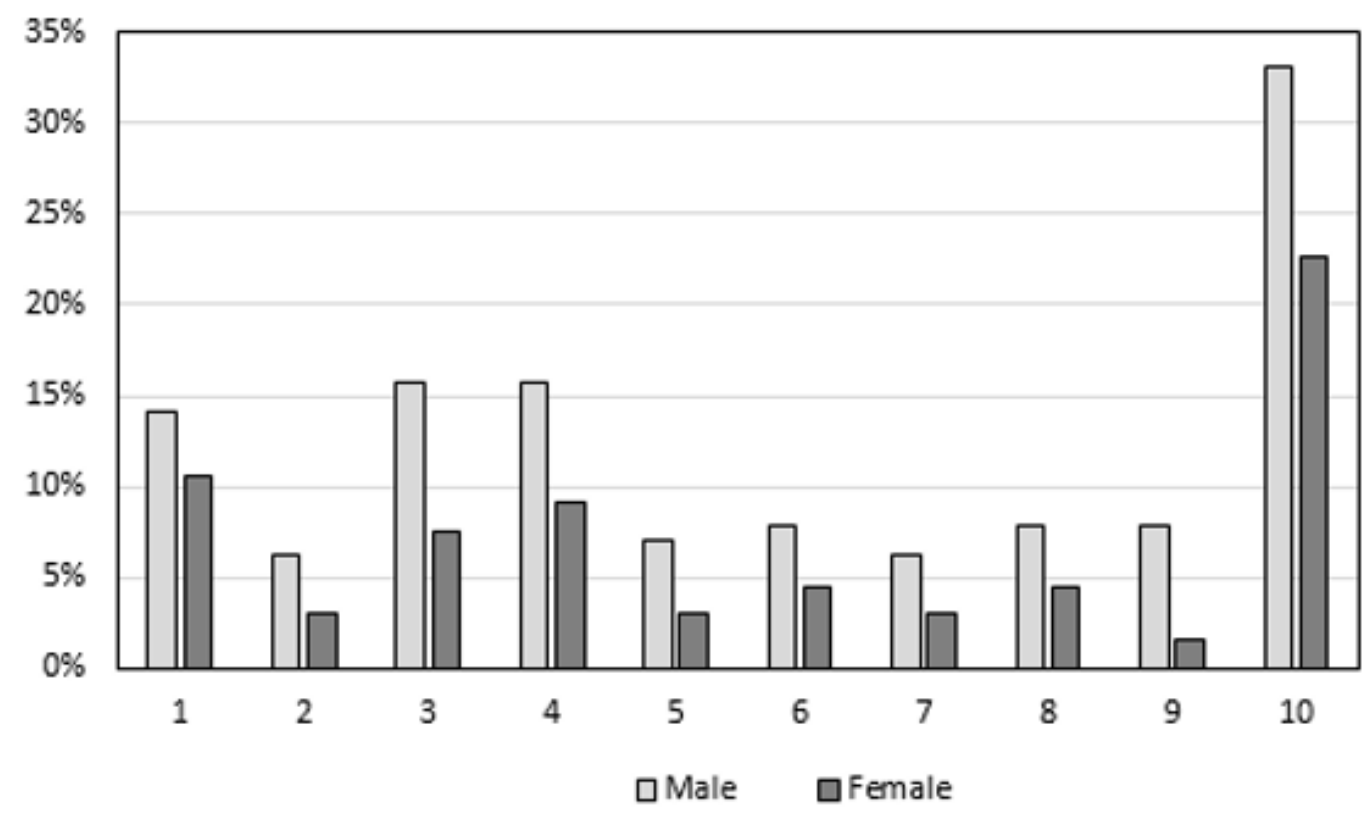

Figure 1: Percentage of male and female students that responded with "Strongly Agree" to all ten statements on the survey. For each statement, the percentage of men responding in this manner is greater than the percentage of women.

From this data, it appears that male students took a more aggressive approach when responding. For all survey statements, they were more likely than female students to select one of the ends of the spectrum. For example, in Statement 9, Comments on course evaluations have a positive effect on a professor's enthusiasm and interest in teaching a course, male students were five times more likely than women to respond "Strongly Agree". Similarly, women were more likely, throughout the entire survey, to select "Neither Agree nor Disagree" (Neutral) as a response. At first, this may seem like an exhibition of the central tendency bias, which is a weakness of the Likert scale, ${ }^{10}$ but the bias doesn't explain why one gender would do so more frequently than the other. Figure 2 shows a graph of the percentage of each gender that responded neutral to each statement on the survey. The number of female students consistently exceeded the number of male students selecting a neutral response, with a range of two to seventeen percent more, regardless of the statement on the survey.

\section{Student's Academic Year}

Newly matriculated undergraduate students, not having finished a course at the collegiate level nor completed a course evaluation, may have preconceived notions about the intent and effectiveness of course evaluations that differ from upperclassmen. These perceptions could be formulated from a mixture of what upperclassman have told them and their own experiences in high school. There could also be conditioning from prior online experiences where a product or service was rated on a social media site, either favorably or unfavorably, and what followed was a modification in crowd behavior i.e. people stopped going to a new restaurant due to poor online reviews so the restaurant fired the chef and changed the menu. 


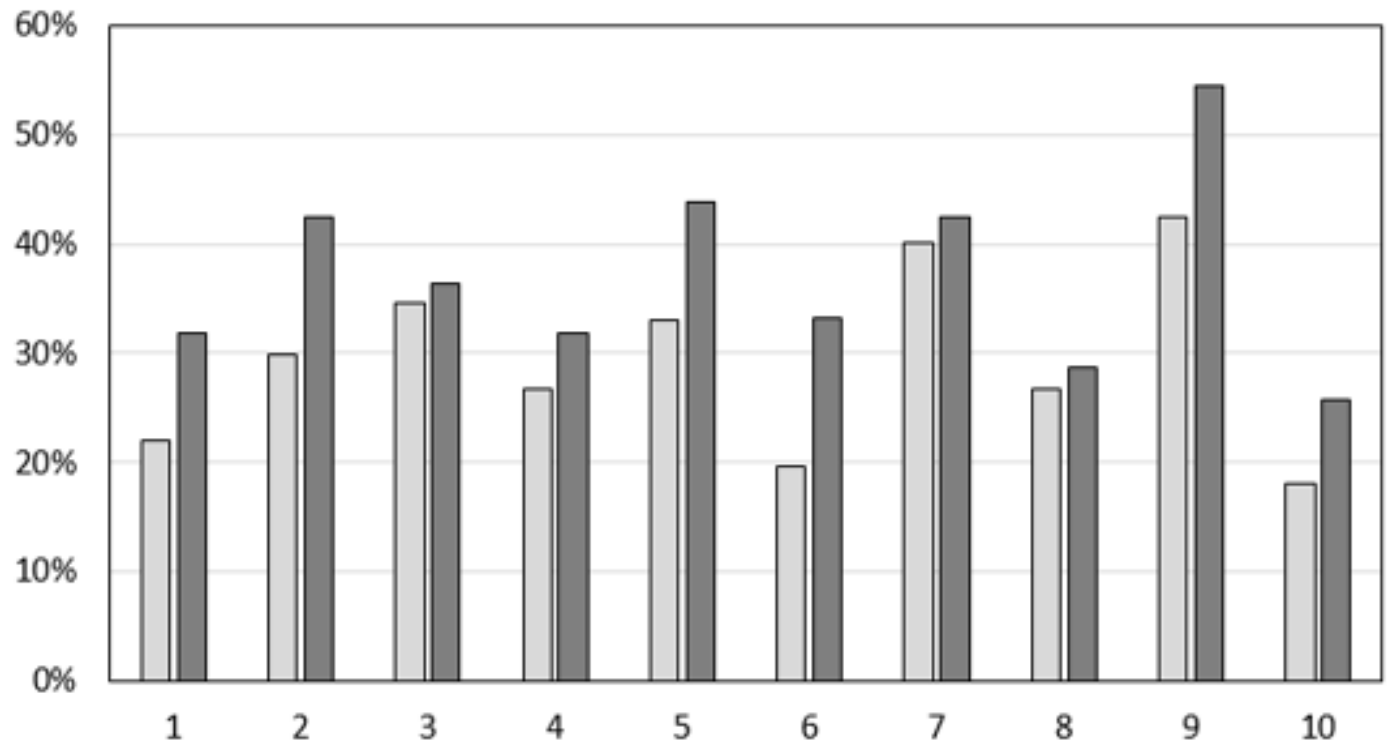

Figure 2: Percentage of male and female students that responded "Neither Agree nor Disagree" to all ten statements on the survey. For each statement, the percentage of women responding in this manner is greater than the percentage of men.

Survey response data was sorted by academic year to test assertions that responses by freshman (Y1) may be notably different from responses by upperclassmen (Y2, Y3, and Y4 combined). For graphical analysis of response frequency, the five point Likert data was reduced to three groups by combining the categories "Strongly Agree" and "Agree" into one category called "Agree." Likewise, responses for "Strongly Disagree" and "Disagree" were grouped into one category called "Disagree." For brevity, the graphs show the response "Neither Agree nor Disagree" as "Neutral."

In general, freshman (Y1) responded more optimistically than upperclassmen (Y2-Y4) when assessing the intent and effectiveness of course evaluations. For example, as shown in Figure 3, close to seventy-six percent of freshman agreed with Statement 1, Course evaluations improve the quality of learning for any given course over time. Whereas only sixty percent of upperclassman agreed with the statement, a difference of $16 \%$. Likewise, twice as many upperclassman chose to disagree with the statement than freshman, Figure 3. 


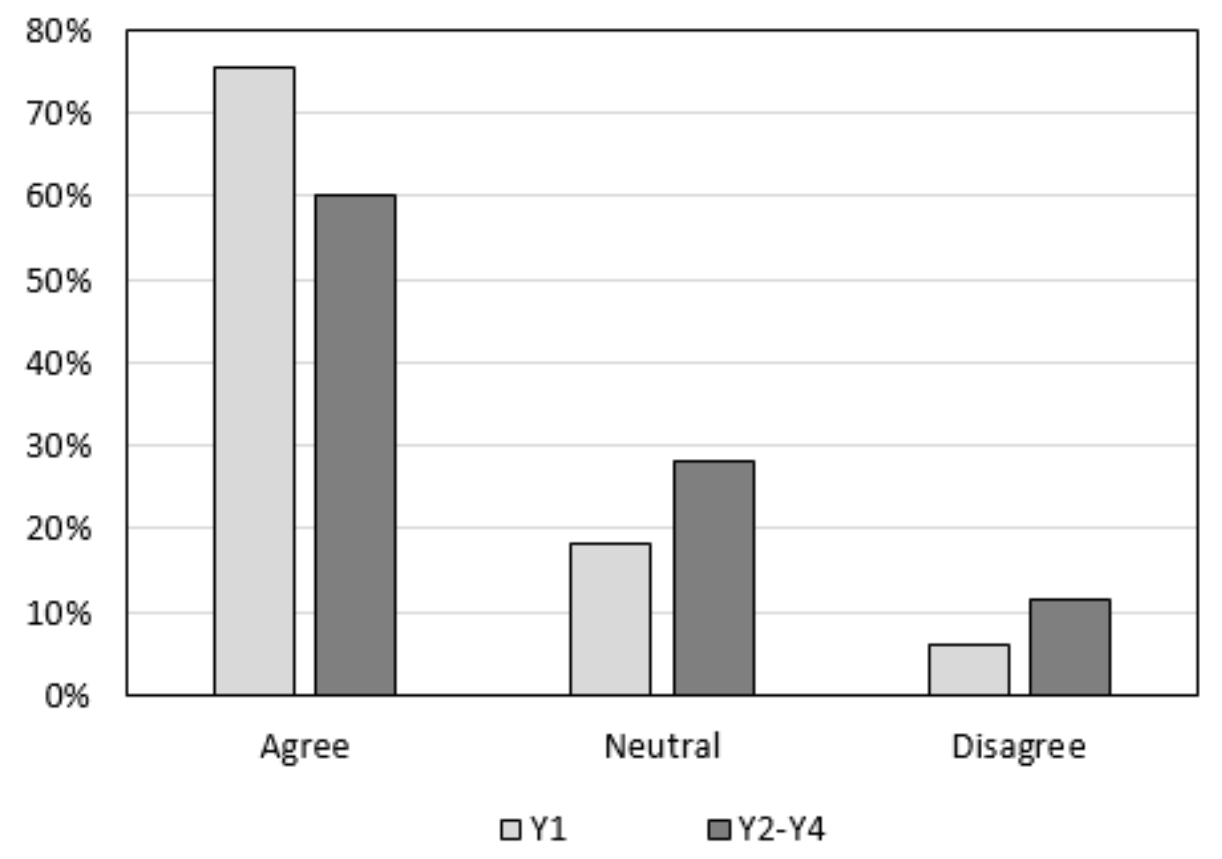

Figure 3: Comparison of freshman (Y1) and upperclassmen (Y2-Y4 grouped) responses to Statement 1: Course evaluations improve the quality of learning for any given course over time

Following this trend, year one students were more likely to disagree with negative statements associated with course evaluations. Figure 4 is a graph of the percentage of student responses to Statement 6: Course evaluations do not influence the teaching style professors use to instruct a course. Here again, freshman chose to take the more optimistic route, where twenty-five percent more upperclassman agreed with the statement.

During one of the faculty interviews, a professor made the comment that once freshman have completed their first course evaluation, "they tend to complain more, when commenting on further evaluations, because they are not used to getting lower grades." This suggests that a freshman's preconceived notion of course evaluations can change significantly after grades are issued. The professor obviously believed that grades impacted responses on course evaluations. The professor also expressed a belief that as students get older and distance their learning from their grade point average, they write better comments on course evaluations.

From the data, it is clear that a majority of students, regardless of how faculty feel, agree that when faculty ignore course evaluations it should affect their pursuit of tenure. Figure 5 shows the percentage of the responses in each category to Statement 10: If professors do not respond to constructive feedback on course evaluations, and thereby do not improve themselves or their courses over time, they should not receive tenure nor pay raises. 


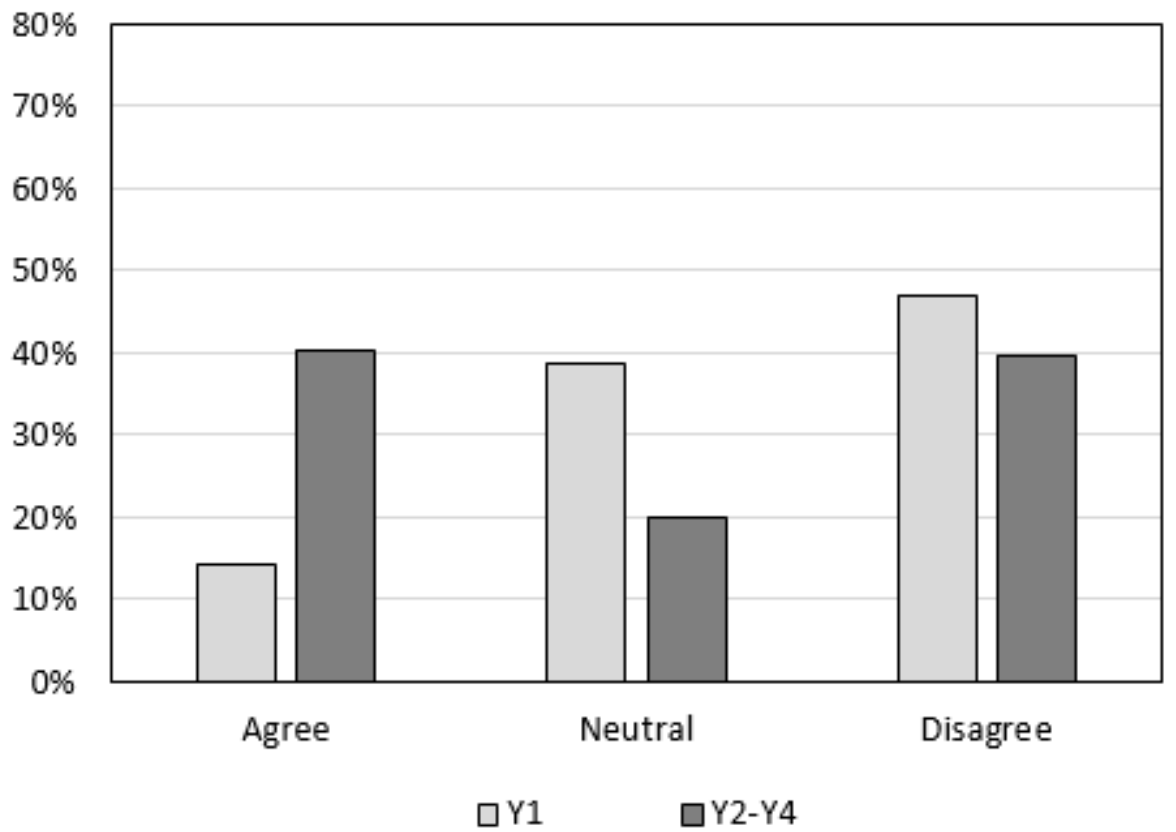

Figure 4: Comparison of freshman (Y1) and upperclassmen (Y2-Y4 grouped) responses to Statement 6: Course evaluations do not influence the teaching style professors use to instruct a course

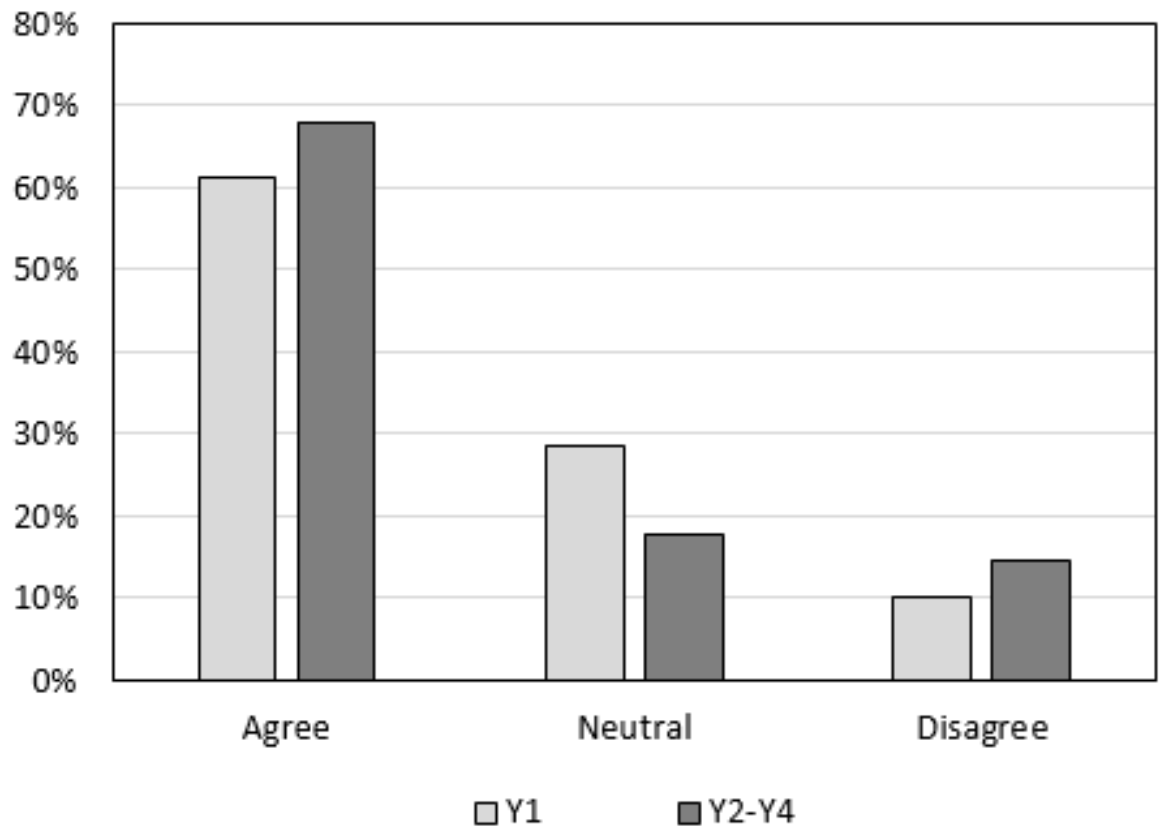

Figure 5: Comparison of freshman (Y1) and upperclassmen (Y2-Y4 grouped) responses to Statement 10: If professors do not respond to constructive feedback on course evaluations, and thereby do not improve themselves or their courses over time, they should not receive tenure nor pay raises 
The data related to Statement 10 is clear, students, regardless of academic year, feel that their feedback matters and should be considered by the administration when it comes to rewarding good teaching.

\section{Faculty and Student Perceptions}

Both students and faculty have very similar standards and expectations when it comes the quality of learning in a course. Following is a series of graphs that depict data where there was a gap between the student and faculty response.

According to Figure 6, there was only a small difference of four percent between students who agreed and faculty who agreed with Statement 1: Course evaluations improve the quality of learning for any given course over time.

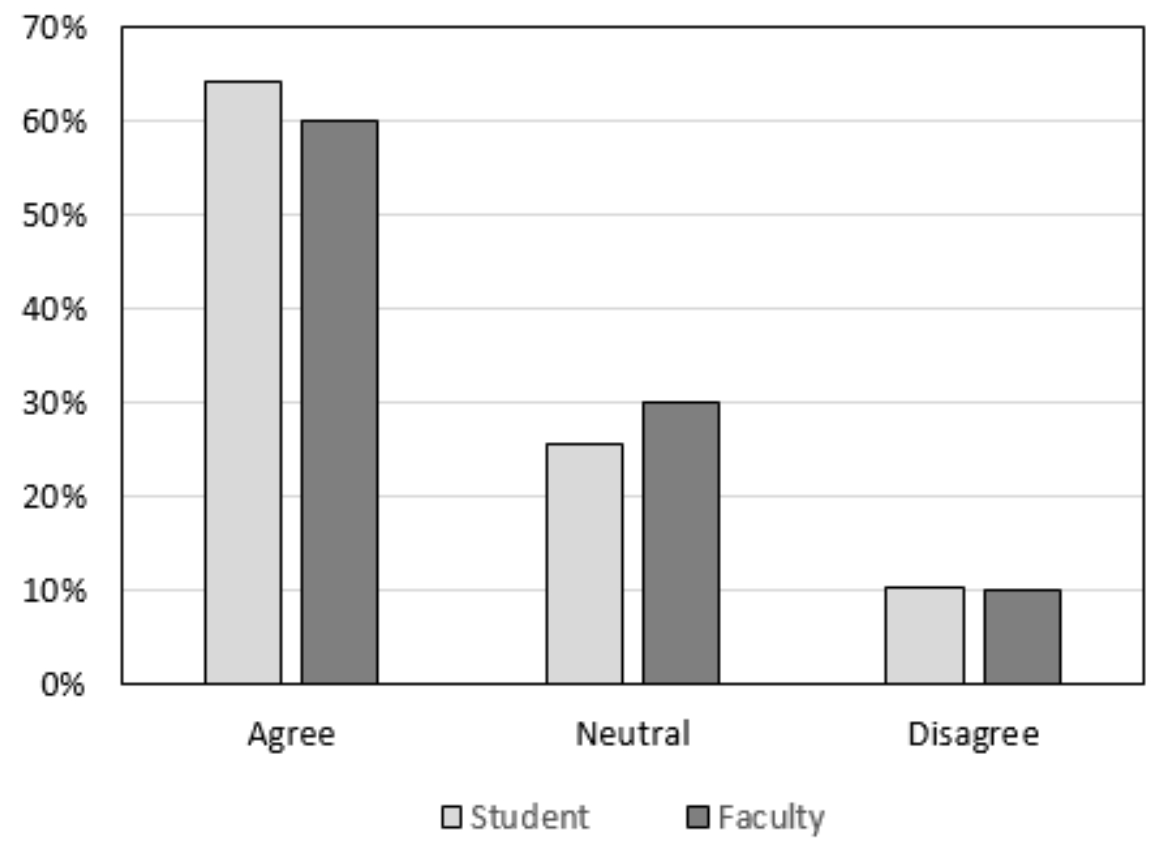

Figure 6: Comparison of student and faculty responses to Statement 1: Course evaluations improve the quality of learning for any given course over time

In James W. Marlin's study, Student Perceptions of End-of-Course Evaluations, it was found that fourteen percent of students thought that course evaluations had no impact on their courses because professor's ignored them. ${ }^{11}$ Similarly, one of the interviewed students noted, "I think some [students] fill [course evaluations] out just to get them done, and that's not accurate at all, but I think some students do take the time to fill them out." This focuses on how students may not realize that course evaluations should be taken seriously, and as a result some professors may not have faith in the system as indicated by the ten percent that disagree with Statement 1, Figure 6. This was explained best by one faculty member who reminisced on his first course evaluation at a different institution, "None of the students took it seriously, it was like three questions on a half sheet of paper. I found it to be nearly useless... the course evaluation wasn't as extensive or 
as helpful as it is here." Conversely, in an interview with one tenured professor, he mused that only about one in ten students ever share any meaningful information on a course evaluation.

The ten percent of faculty that don't believe in the course evaluation system as an instrument to improve quality of learning may be indicative of how they feel about being evaluated by students. The data clearly shows that the majority of faculty feel they are not accurately assessed on course evaluations because of a grade bias. Figure 7 shows that faculty members strongly disagreed with the Statement 8: Regardless of a student's grades, professors are accurately evaluated with course evaluations. Over sixty percent of faculty disagreed with this statement, whereas students had a more even distribution between the three responses. In Marlin's study, he found that, "more than half the students felt that the forms used for rating instructors provided them with an effective means of evaluation,". ${ }^{11}$ However, several faculty members during the interviews made note that some of their colleagues felt, "students don't know what good teaching is," and "a majority of students will complain about the amount of work in a class," which has got nothing to do with teaching.

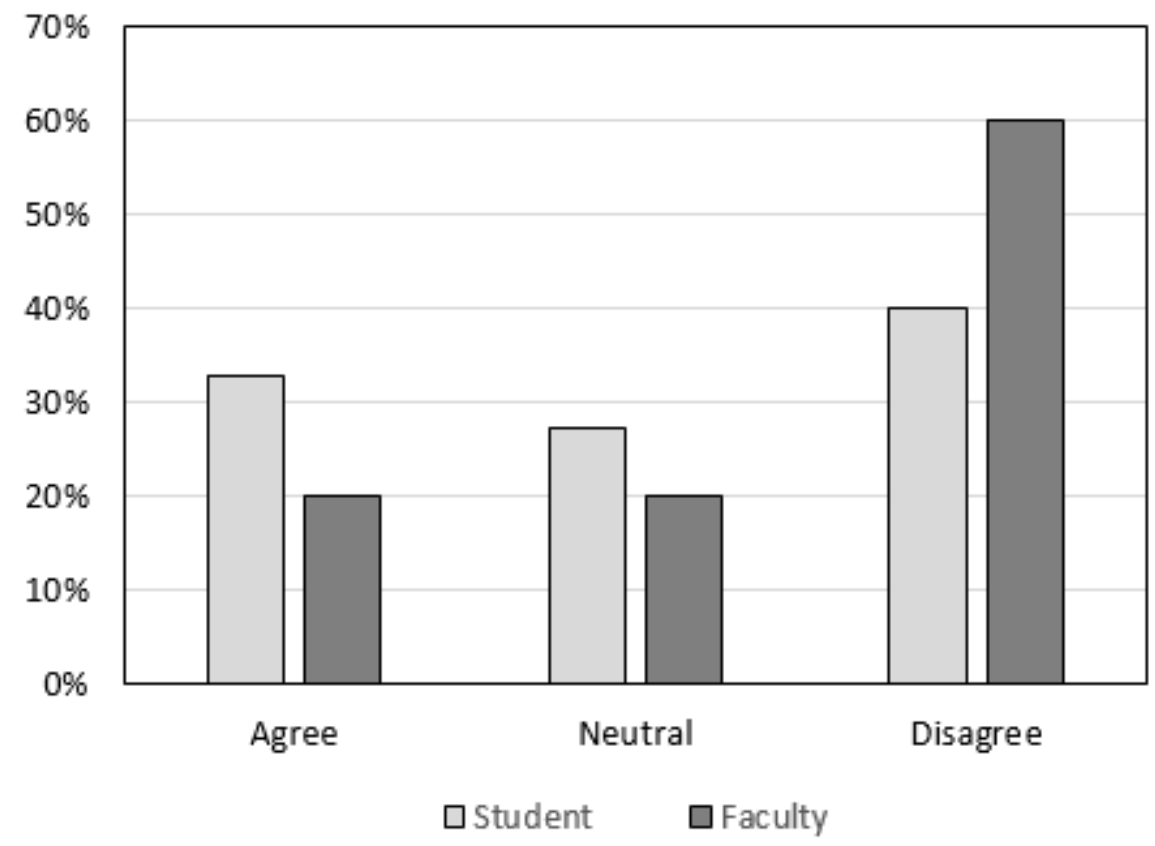

Figure 7: Comparison of student and faculty responses to Statement 8: Regardless of a student's grades, professors are accurately evaluated with course evaluations

Interestingly enough, several interviewed professors made mention of nasty comments that are made on course evaluations. "One of my colleagues got an evaluation that said she wore too much eye makeup. That's the problem with the class?" He continued to say that nasty comments along those lines tend to, "stick with you." This explains how faculty could start to doubt the course evaluation system, or feel that they won't be able to improve if students can't make constructive comments.

There was a strong difference between the student and faculty when both were asked to reflect on how preparation material changes due to course evaluations. Here, students have a harder 
time seeing these changes than faculty members. In response to Statement 5: Regardless of course evaluations, professors do not change their preparation material for class, Figure 8 reveals that not a single faculty member agreed with the statement and only ten percent chose neutral. However, the student responses are quite dispersed. This reveals a gap in perception, because students cannot tell if professors are actively changing their own preparation material to improve the class. The strong disagreement from the professors is understandable, since they know what they have changed to improve the courses taught at their institution. One faculty member has been instrumental in the creation and reinvention of two Electrical and Computer engineering courses at our institute, and during his interview he made note that faculty members are changing the course material all the time to try and keep it up to date, "Digital Systems only exists because of course evaluations, I taught a previous course called Logic Design... and the class itself [received] a lot of negative [evaluations], because it was all in Verilog and not schematic capture. The students really struggled with that and hated it; I spent really late nights helping them. This gave me enough ammunition to change the class."

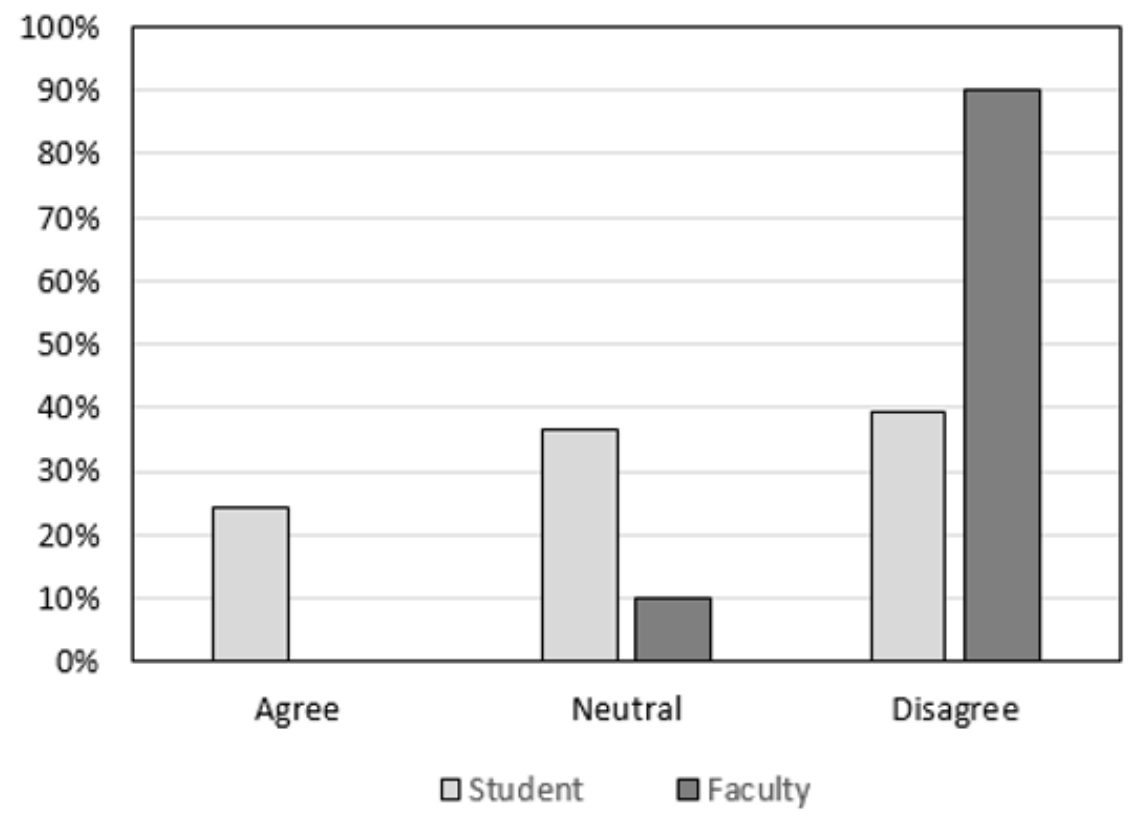

Figure 8: Comparison of student and faculty responses to Statement 5: Regardless of course evaluations, professors do not change their preparation material for class

The distribution of faculty responses to the survey and primary investigations reveal that course material, homework and even the entire class set up can change because of course evaluations. To faculty, it is clear that their preparation material changes from one school term to the next; alternatively, students do not seem to see (realize) the changes. Their experience is discontinuous, whereas faculty teach the same course many times in a career. One reason the majority of students do not agree with faculty on this statement could be because the changes that do happen to the preparation material get smaller and smaller each year. Another faculty member noted "... Now that I've been teaching for a long time, course evaluations allow me to fiddle with the knob ever so slightly." Everyone notices when you make a big change, like 
creating a new class, but on a term-to-term basis it becomes harder and harder to see what the changes were.

Unlike faculty responses, the majority of students that responded to the survey thought that course evaluations should play a factor in the tenure process. In response to Statement 10: If professors do not respond to constructive feedback on course evaluations and thereby do not improve themselves or their courses over time, they should not receive tenure nor pay raises, as seen in Figure 9, only thirteen percent of students thought that course evaluation data should not play a factor in the tenure decision. The faculty responded in almost a bimodal fashion, where forty percent of faculty agreed to the statement and thirty-five percent disagreed. An almost evenly divided distribution between the two ends of the spectrum reaffirms that faculty members feel they are not always accurately assessed by the students. There is evidence that in large, lecture styled classes, as opposed to a more intimate setting with a small class size, course evaluations will be lower and perhaps should not carry as much weight in tenure and promotion decisions. $^{12}$

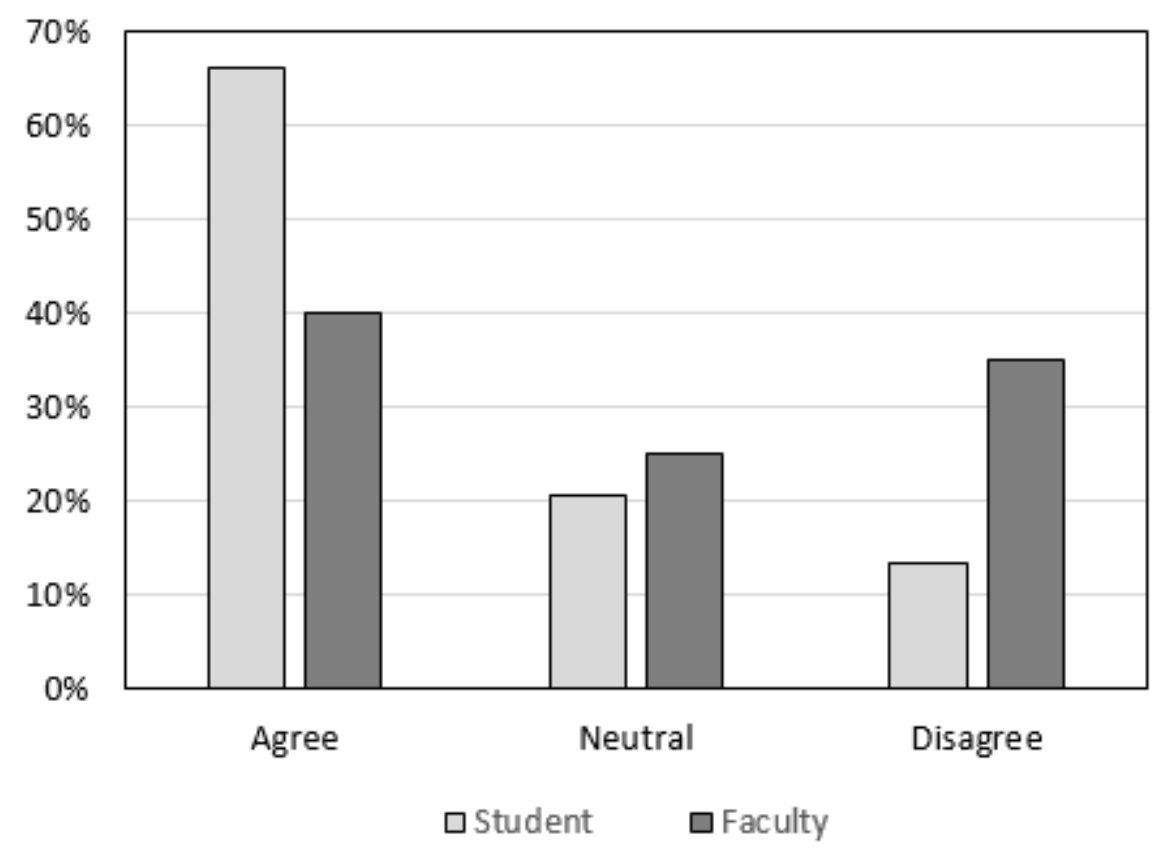

Figure 9: Comparison of student and faculty responses to Statement 10: If professors do not respond to constructive feedback on course evaluations and thereby do not improve themselves or their courses over time, they should not receive tenure nor pay raises

Faulty members that agree with Statement 10 likely understand that students want to be involved in the tenure process and it is probably appropriate that they have a voice. Students may see tenured professors that have received poor evaluations are continuously returning, and hence, currently feel that they have no impact. ${ }^{11}$ Students want to participate and be a part of the decision making process, without realizing their current role. One faculty member revealed that 
he, “... didn't even know how much of a factor [course evaluations] had in the process until I got tenure." This suggests that the students and faculty are not on the same page.

\section{Conclusions}

Analysis of survey data shows multiple cohorts have different perceptions on course evaluations, such as male and female students, freshman and upperclassman, and students and faculty. In response to how students and faculty have responded to the survey, there appears to be areas where students and faculty agree on the effectiveness of course evaluations, but there are several gaps. Most notably, students think that course evaluations should have an impact on the tenure process, but the faculty are split on this point. In addition, the faculty feel strongly that they respond to student evaluations and make appropriate changes to their courses, but from the student's perspective there was no general agreement. Finally, when it comes to the issue of grades having an effect on course evaluations, the faculty feel there is a dependency, but the students are not in agreement. Closing the gap between student and faculty perceptions is important to help maximize the utility that can be obtained from using the course evaluation system, which will lead to stronger impact on the improvement of faculty teaching methods and the quality of learning available for students. A faculty led discussion of the course evaluation system in first semester freshman College and Life Skills courses may have an impact on closing the identified gaps.

\section{References}

1 Nyquist, J. D., Manning, L., Wulff, D. H., Austin, A. E., et. al., “On the Road to Becoming a Professor: The Graduate Student Experience,” J Change: The Magazine of Higher Learning, Vol. 31, Issue 3, 1999.

2 Brent, R., Felder, R. M., Rajala, S. A., "Preparing New Faculty Members to be Succesful: A No-Brainer and Yet a Radical Concept,” ASEE Annual Conference, Chicago, IL, June 18-21, 2006.

3 Gehringer, Edward, "Improving Scores on Course Evaluations: Experienced Faculty Tell What Works," ASEE Annual Conference, Austin, TX, June 14 - 17, 2009.

4 Hill, Warren, "Student Evaluation of Teaching - Myths and Realities," ASEE Annual Conference, Chicago, IL June 18-21, 2006.

5 Dee, C., Kay, "Reducing the Workload in Your Class Won't 'Buy' You Better Teaching Evaluation Scores: Re-Refutation of a Persistent Myth,” ASEE Annual Conference, Salt Lake City, UT, June 20-23, 2004.

6 Kockelman, Kara Maria, "Student Grades and Course Evaluations in Engineering: What Makes a Difference,” ASEE Annual Conference, Albuquerque, New Mexico, June 24-27, 2001.

7 Visco, P., Donald, "Improving Student Evaluations by Demonstrating Concern for Students," ASEE Annual Conference, Salt Lake City, Utah, June 20-23, 2004.

8 Freeman, S., S. L. Eddy, M. Mcdonough, M. K. Smith, N. Okoroafor, H. Jordt, and M. P. Wenderoth. "Active Learning Increases Student Performance in Science, Engineering, and Mathematics," Proceedings of the National Academy of Sciences 111.23 (2014): 8410-415.

9 Dunning, Scott, "Reevaluating the Student Evaluation Process," ASEE Annual Conference, Vancouver, B.C., Canada, June 26-29, 2011. 

39.2 (1997): 331-42.

11 Marlin, James W., Jr. "Student Perceptions of End-of-Course Evaluations." The Journal of Higher Education 58.6 (1987): 704-16.

12 McCallum, L. W. "A Meta-Analysis of Course Evaluation Data and its Use in the Tenure Decision," The Journal of Research in Higher Education 21.2 (1984): 150-58.

\section{Appendix A: Course Evaluation Questions}

Please rate the questions from 1 to 5,1 being the lowest, 5 being the highest:

1. Rate the quality of your learning in this course.

2. The laboratory assignments and course material reinforced one another.

3. The workload for this course in relation to other courses of equal credit was

4. Overall, how would you rate this course?

5. Describe one or more strengths of this course.

6. Describe one or more ways this course can be improved.

7. The professor used teaching methods which helped me learn.

8. The professor was well prepared for class.

9. The professor was available for help outside the classroom.

10. The professor seemed genuinely interested in teaching this subject.

11. Please rate the professor's overall performance in this class. 


\section{Appendix B: Survey Monkey - Online Survey}

* 2. you are a...

Student

Faculty member

3. Are you an international student? (Skip if you are faculty)

Yes

No

4. What is your identified gender?

Male

Female

Other

5. What year do you intend to graduate (Skip if you are faculty)?

2017

2018

2019

2020

2021

6. Have you completed an online course evaluation at Rose-Hulman

Yes

No

7. Please Select your primary major (Skip if you are faculty). 
* 8. Please select how you feel regarding the statements about course evaluations

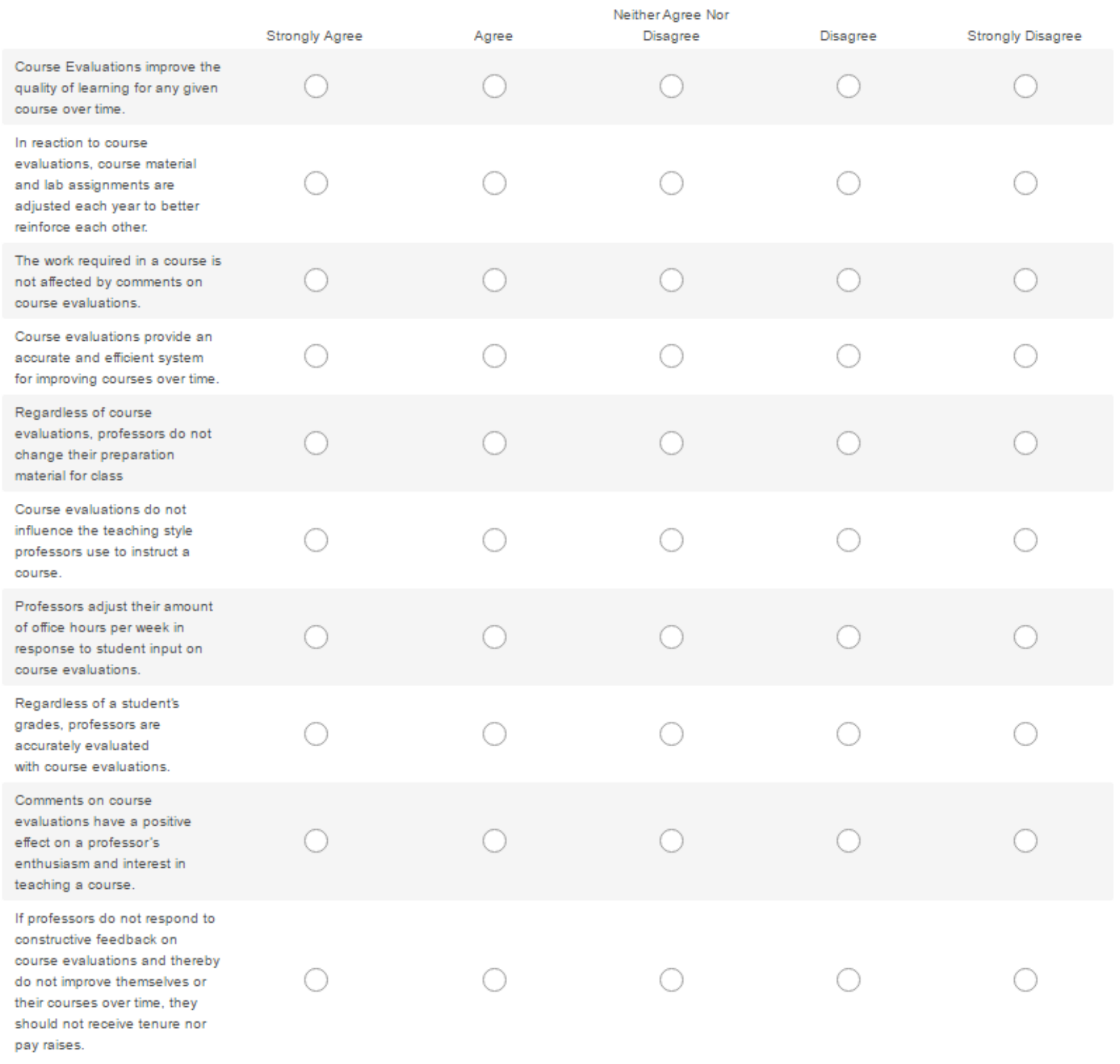

